\title{
Habits and Narrative Agency
}

\author{
Nils-Frederic Wagner ${ }^{1}$
}

Published online: 18 February 2020

(c) The Author(s) 2020

\begin{abstract}
Some habits are vital to who we are in that they shape both our self-perception and how we are seen by others. This is so, I argue, because there is a constitutive link between what I shall call 'identity-shaping habits' and narrative agency. Identityshaping habits are paradigmatically acquired and performed by persons. The ontology of personhood involves both synchronic and diachronic dimensions which are structurally analogous to the synchronic acquisition and the diachronic performance of habits, and makes persons distinctly suitable to being shaped by habits. Since habits differ vastly in their scope, I develop a conceptualization that carves out defining features of identity-shaping habits. Such habits, I venture, fundamentally alter a person's embodiment such that the alterations to their psychological and physiological make-up vitally inform their persistence-if not metaphysically (as in constituting necessary and jointly sufficient conditions of personal identity over time), then at least practically by crucially shaping one's narrative agency.
\end{abstract}

Keywords Habits $\cdot$ Narrative agency $\cdot$ Self-constitution $\cdot$ Personhood $\cdot$ Personal identity

\section{Introduction}

As creatures of habit, we are intimately familiar with the phenomenon. Since the performance of habits largely defies conscious deliberation, this first-personal familiarity, however pervasive, remains largely unreflective. I argue that upon reflection, there is more to habits than meets the eye. As spearheaded by Pollard (2006), philosophers have been mainly concerned with reconciling the undeliberate nature of habits with standard theories of action. I tackle a different issue. If my arguments in what follows are on the right track, it turns out that certain habits are vital to who we are. Consider the following example of habit acquisition and continuous performance to both illustrate and elucidate the concept at hand. ${ }^{1}$

Watching the Giro d'Italia on TV, 14-year-old Klea is so intrigued that she would love to start road racing herself. It doesn't take much to convince her parents to set her up with a road bike, since she sensibly argues that biking regularly will be conducive to her well-being. So cycling becomes part

Nils-Frederic Wagner

nils-frederic.wagner@web.de

1 Department of Philosophy, University of Twente, Cubicus C-319, Drienerlolaan 5, 7522 NB Enschede, The Netherlands of her weekly, habitual routine. The habit-initiation has taken place consciously and voluntarily. Initially, Klea cycles three times a week; by so doing, the relevant bodily movements become automatized. After a while, Klea can slowly raise the frequency and intensity of cycling in accordance with the improvement of her coordinative skills and the growth of her muscle strength. Also, the movements of her arms and legs require increasingly less conscious effort; more and more, Klea can focus on something else. In fact, she takes great pleasure in letting her mind wander while riding her bike. The automatized act of cycling induces a form of learning and improvement in the motion sequences involved. This automaticity is accompanied by a form of conditioning: Klea feels the reward of doing sports, gets used to this reward, and is thereby conditioned to keep going. The activation of the brain's reward system that comes with doing sports regularly has, presumably, something to do with the voluntariness of engaging in the activity of one's liking. Slaving away in a mine excavating stones, for example, can become automatic and thus arguably considered habitual; nonetheless, most likely, it will not be particularly rewarding. Cycling regularly in a well-specified and stable context, for example by using similar bike trails, further contributes to habitualizing the activity. Stable contexts are important to

\footnotetext{
${ }^{1}$ Since I frequently return to this example, for both argumentative and dialectical purposes, I spend some time on thickly describing the
} case. 
smoothen the automatized act of cycling because that way Klea does not have to constantly adjust to new situations. Say she is used to biking on asphalt trails, but due to having no access to such trails while on vacation, she is forced to bike off-road. At this point, the very act of cycling becomes less smooth. Such disturbances aside, as time goes by, Klea not just continuously improves her cycling skills, meticulously monitoring her progress, scheduling her training for months ahead, joins a club, partakes in competitions, tells her family and friends about her latest accomplishments, but also increasingly considers herself to be a cyclist. Slowly but steadily, cycling significantly contributes to the way she experiences and expresses herself, and affects how others perceive her. Cycling, then, becomes integral to the person she is. Call habits that are formative for, and vital to, a person's self-constituting narrative 'identity-shaping habits'.

Here is how I proceed: in section two, I square the case for identity-shaping habits with standard theories, canvassing recent conceptual work on core features of habits and habitual action. In section three, I shed light on the structural link between these core features of habits, their acquisition, and conditions of personhood. In section four, I turn to develop a conceptualization of identity-shaping habits, arguing why and how such habits are vital to one's narrative agency. In section five, I briefly look at the practical implications of identity-shaping habits for social predictability and stability. In section six, I wrap up.

\section{Core Features of Habits and Habitual Action}

It stands to reason that an account of identity-shaping habits and narrative agency draws on Aristotle's normative notion of character-forming via habituation. But this is not what I am concerned with. Accordingly, I do not wish to belabor the Aristotelian virtue ethical conviction that good habits contribute to forming good characters, and likewise bad habits contribute to forming bad characters. Rather, my argument is ontological, and as such orthogonal to the normative notion of habits: I argue that certain habits vitally contribute to making us the people we are. Whether they do so by making us good or bad people is a question for another day. In fact, I think there is not necessarily, perhaps not even most frequently, a normative element to identity-shaping habits as I conceive of them. Take our initial example: does cycling make Klea a better or worse person? This question does not seem to have a sensible answer. Being a cyclist is vital to the person she is-no more, no less. It is not, of course, that a structural feature of habits prevents them from having normative import; a fair amount of them do have normative import. I merely take it that habits need not have normative import to be identity-shaping.
In what follows, I first investigate what it is for something to be a habit ontologically, setting aside the normative question as to what makes a habit good or bad. Next, drawing on these general ontological features of habits, I argue that a special category of identity-shaping habits contributes significantly to our practical identity by characterizing us as the distinct people we are. Identity-shaping habits do so via pivotal, habitual patterns of thought and action that structure the particular lives we lead. This contrasts with constituting a person's numerical persistence which has typically been cast in terms of metaphysically necessary and jointly sufficient conditions of personal identity over time. ${ }^{2}$

It has sometimes been overlooked that habits do not exclusively manifest themselves in overt behavior, but also in patterns of thought, recurrent emotions, and perceptions. For brevity's sake, let us lump together the latter kind of habit under the label 'habitual thoughts'. So there are, on the one hand, habitual actions that manifest themselves in overt behavior; and, on the other hand, habitual thoughts that do not necessarily translate into overt behavior (of course, they might do so on occasion). Naturally, this distinction is neither meant to be exclusive nor is it meant to present an ontological dichotomy between habitual actions that involve overt behavior, and habitual thoughts that do not necessarily involve or translate into overt behavior. Habitual actions can involve or require habitual thoughts; and vice versa, habitual thoughts can lead to habitual actions. And both forms of habit often take place simultaneously. Nonetheless, distinguishing these two forms of habit makes sense since it draws attention to the frequently underappreciated fact that habits are not always constituted by habitual actions. What I am concerned with in what follows are identity-shaping habits that mostly, though not exclusively, translate into overt behavior; this regularly, though not always, involves habitual thoughts. So my analysis is in some way heedless of the distinction between habitual actions and habitual thoughts. This, however, is not meant to neglect that distinction. Since I think that both forms of habit contribute equally to forming one's narrative agency, I will not have much to say about the intricacies of their entanglement.

Having cleared some preliminary conceptual ground, let us look at paradigmatic accounts of habits that have lately been discussed in analytic philosophy. Even though the philosophical import of habit and habitual action is known since the ancients, analytical philosophers have only recently begun to systematically investigate the concept (Pollard 2006; Snow 2006; Di Nucci 2013; Wagner and Northoff 2014; Matthews 2017; Douskos 2017a, b, c; Kalis and Ometto 2019; Felletti 2019). Pollard, among the

\footnotetext{
${ }^{2}$ I return to the distinction between a person's practical and metaphysical identity in section four.
} 
first to take up the baton, defines habits to a first approximation as a "pattern of a particular kind of behavior which is regularly performed in characteristic circumstances, and has become automatic for that agent due to this repetition" (Pollard 2006, p. 57). Habits, so defined, can explain a vast amount of behaviors; many more than one might initially assume. Think of how much our lives are governed by exercising habits rather than subjecting our actions to deliberation. However, unlike reflexes, for which the same general characteristics apply, habits involve a previous (and in varying degrees conscious, as well as voluntary) acquisition. So habits do not just passively happen to someone. Rather, habits encompass a specific pattern of thought and action that, at some point, has been actively acquired. ${ }^{3}$ Conceptually, habits have thus been ascribed to the realm of action rather than constituting mere movements.

Matthews (2017) has recently offered an explicative definition of habits-sensibly resisting the temptation to posit necessary and jointly sufficient conditions-that consists of the following five features:

(1) Habits are actions, thoughts, perceptions, feelings, or motives that are socially shaped.

(2) Habits are acquired through repetition.

(3) Habit acquisition is associated with internal changes within the agent (to her body and/or brain), making habit modification or elimination difficult.

(4) Habits are activated by environmental triggers.

(5) Though automatic, habits are sensitive to intervention.

I employ Matthews' definition of habits as the baseline for my own analysis. In venturing my account of identity-shaping habits in section four, I adopt Matthews' third feature which I take to be directly linked to narrative agency. But before I get to argue that our initial example showcases a special kind of habit worth considering separately, I run through the example to check whether it satisfies Matthews' defining features and thus qualifies as a case in point.

Call (1) the social feature. "The social nature of habits makes them inherently relational", tells us Matthews (ibid., 13). Returning to our example, this might mean two things. Firstly, road racing as a sport is socially and culturally

\footnotetext{
3 Thanks to an anonymous referee for pointing out that not all habits are actively acquired; and not only those who are so acquired make us the people we are. In between mere reflexes and full-blown identityshaping habits, there is (at least) one category of habit that does not depend on active acquisition. Unconsciously acquired habits, such as punctuality or behavioral quirks, for example, can also contribute to who we are. What I am concerned with, however, is the link between actively acquired habits and certain aspects of a person's narrative agency (being a cyclist in Klea's case). This is not to disregard that other habitual elements besides those that are identity-shaping also inform someone's distinct personality.
}

embedded, and as such does not happen in isolation. If Klea were living in some remote area where no one cycles, she most likely would not have been exposed to that sport on TV. Furthermore, if the social infrastructure, like stores, clubs and all the rest of it were not in place, she would hardly have acquired the habit in the first place. Secondly, the social nature of habits might also refer to how the actual acquisition of the required skillset depends, to some extent, on others teaching her how to properly ride a road bike. Once these skills have been acquired, cycling can easily be performed in isolation (even though there remains, of course, a residue of social interaction when she navigates her way through shared tracks). Call (2) the repetition feature. That acquiring the habit of road racing requires repetition goes without saying. Klea does so thrice weekly and subsequently increases that frequency. Call (3) the internal alteration feature. Once Klea cycles regularly, her body and brain adapt. Her coordinative skills increase, her muscle strength grows, and her brain's reward system longs for the thrill. All sorts of further psychological adjustments occur as well. ${ }^{4}(4)$, which I call the environmental feature, is in place as well. Klea does not randomly cycle on her doorway but does so at specific times, using special gear (first and foremost her bike), and she cycles in response to environmental triggers such as being on a bike trail. The initiation of her cycling is embedded in other activities as well; for example, she finds herself automatically putting on her gear when she gets home from school. (5), the automatic, interventional feature is twofold. On the one hand, cycling does not require much conscious attention regarding pertinent bodily movements. Giving way to the force of habit, Klea is mostly on autopilot, as it were. On the other hand, her cycling technique is amenable to adjustments that require her conscious intervention. She might, for example, utilize considerable conscious effort while learning a new way to position herself on the bike when speeding downhill.

It seems that our example satisfies Matthews' core features of habits, qualifying as a case in point. I now turn to set the stage for specifying what unifies identity-shaping habits, rendering them a special kind of habit with added explanatory power that goes beyond merely checking the boxes of standard theories of habit. In so doing, I look at what makes persons distinctly suitable to acquire habits in general; and subsequently, I analyze what makes persons susceptible to identity-shaping habits in particular.

\footnotetext{
${ }^{4}$ I get back to the internal alteration feature and its relevance for narrative agency in section four. My task here is to firstly see whether our initial example coheres with Matthews' five core features of habits.
} 


\section{Personhood, Habit Acquisition and Performance}

Persons are paradigmatic carriers of habits. We need to know, then, how their ontological constitution contributes to habit acquisition and performance. I make no attempt here to comprehensively, let alone decisively, answer the vexing question of what it takes to be a person at a distinct point in time, nor how persons metaphysically persist through time. Nonetheless, a few remarks are in order that shall help paving the way to structurally relate conditions of personhood to the previously mentioned core features of habits and their acquisition.

Ontologically, there is the need for providing both synchronic conditions of personhood that shed light on features an entity must possess to qualify as a person at a distinct point in time. ${ }^{5}$ And, depending on these synchronic conditions, diachronic conditions tell us how persons, so defined, persist through time. Synchronically, persons are often characterized by a set of mental features possessed by all and only persons. These features, both traditionally and in recent philosophical discussions, are mostly presented in terms of higher-order cognition. Accordingly, many philosophers think that a person is someone who acts from reasons. This conception has a long tradition, reaching back to Locke who famously said that a person is "a thinking intelligent being, that has reason and reflection, and can consider itself as itself, the same thinking thing, in different times and places" (Locke 1694/1975, p. 335). Locke employed his higher-order cognitive understanding of personhood as a foundation for his account of personal identity over time. Locke's view has a great number of modern-day successors, sometimes referred to as "Neo-Lockeans" (Shoemaker 1970, 1984, 1997, 1999; Parfit 1984; Lewis 1976). So let us establish that a set of higher-order cognitive features is widely accepted as necessary (on some accounts sufficient) for personhood. Taking Locke's proposal as the paradigmatic view, one might conclude that

necessarily, $x$ is a person at time $t$ if and only if $x$ has the capacity for rationality and diachronic self-consciousness that allows them to first-personally conceive of themselves as themselves over time.

Habit acquisition and performance relates to the Lockean view of personhood in both synchronic and diachronic ways. Social psychologists point out that habits come with

\footnotetext{
${ }^{5}$ Since the view of identity-shaping habits I develop is descriptive, I focus on ontological conditions of personhood and remain agnostic as to personhood's normative conditions. For a recent analysis of the interplay between personhood's ontological and normative conditions, see Wagner (2019).
}

self-regulatory benefits that help to avoid the stress and resource consumption of having to make decisions in similar situations time and again (Armitage and Conner 2001). So persons often rely on habits as efficient ways to go about their daily routines. The conscious acquisition of habits, i.e., the conscious decision to maintain a specific pattern of action in stable contexts, thus relies on both rationality and planning agency. ${ }^{6}$ The very idea of habit acquisition is to avoid the process of deliberative decision-making in recurring situations for which a rational decision, or a plan, has already been made. Acquiring and sticking to habits can thus be described as employing one's practical rationality as an appropriate way of processing information through reasoning. Likewise, in most cases, persons will be able to sensibly answer the question why they perform a certain habit regularly. ${ }^{7}$ To illustrate the point, consider again our example. As a rational agent, Klea knows that it is healthy to do sports regularly. But, unless she purposely forms the habit to do so at specific times, each time doing sports comes to mind will initiate the same decision-making process again, and it may become difficult to motivate herself repeatedly. Since Klea's intention is to stay healthy, it is both rational and efficacious to acquire the habit of cycling. The rational acquisition of habits rests upon a, using Frankfurt's (1971) vocabulary, second-order volition; i.e., the forming of an, in this case affirmative, second-order will about a first-order will. This involves the kind of self-reflective deliberation we know from Lockean conditions of personhood. Rather than repetitively making rational decisions about similar courses of action at specific points in time, habits prompt rational decision-making over time. The Lockean features of reason and reflection function as conditions of possibility to acquire habits. They are also involved in maintaining habits over time, as I argue in what follows. However, reason and reflection are at best marginally involved in the synchronic performance of habitual behavior. Quite the contrary, habits relieve us of the cognitive burden of having to re-adjudicate conclusions reached by reason and reflection. Habits become encoded and embodied and, in that way, automatic. Locke's emphasis, however, is on the experience of self-reflection and on the continuing operation of reason and reflection. So the role reason and reflection play when identity is connected to habit is rather un-Lockean. ${ }^{8}$

\footnotetext{
${ }^{6}$ Frankfurt (1982) makes a related claim about how commitments carry us into the future that I will pick up in section four. Bratman (1989) similarly claims that personal policies help us extending the influence of rational reflection on action.

7 This, at the very least, applies to habits one is aware of and endorses in some relevant sense.

${ }^{8}$ I owe this point to an anonymous referee who sensibly argues that it is a bit of a stretch to label the role reason and reflection play in identity-shaping habits Lockean or Neo-Lockean. Nothing much hangs on this label, though. What matters is that reason and reflection are
} 
Having in place an idea as to what defines persons synchronically, as well as an idea of how this relates to the synchronic acquisition of habits, we can now take a closer look at what makes it possible for persons to perform habits diachronically. The individual actions that constitute habits are carried out synchronically. But for these actions to truly become habits, they must be performed regularly, and thus occur diachronically. So, with regards to Lockean conditions of personhood, it seems obvious that habits need for their generation some form of diachronic self-consciousness and planning agency. Take our example once more: only if Klea can conceive of herself as herself over time does it make sense to form distal intentions about her cycling activities. Scheduling her training for months ahead, say, involves anticipating a future self executing plans that she contrives now. More generally, only if persons who synchronically perform particular actions appreciate themselves as persisting over time, are they able to diachronically perform actions that eventually constitute habits. To put it more formally:

only if synchronic person $x$ at time $t$ is linked in the right way with synchronic person $y$ at time $t^{*}$, can actions be performed diachronically, and thus possibly constitute habits.

One might think that this right way of linking temporal person-stages ${ }^{9}$ is covered by the formal notion of diachronic self-consciousness, familiar from Lockean conditions of personhood. However, diachronic self-consciousness, as I argue in what follows, does not suffice to explain why certain habits are vital to how we are and others are not. It merely explains how persons can acquire habits per se. To overcome this shortcoming, I now turn to look at what, in addition to the formal notion of diachronic self-consciousness, this right way of linking temporal person-stages consists in. I will suggest that narrative agency might do the trick by enabling certain habits to become identity-shaping.

\footnotetext{
Footnote 8 (continued)

orthodox conditions of personhood that figure prominently in acquiring and maintaining habits, and as such make persons paradigmatic carriers of habits.

9 The talk of 'person-stages' is borrowed from the literature on metaphysically necessary and sufficient conditions of personal identity over time (Lewis 1976). The way I use the term is not meant to insinuate any of the metaphysical commitments that are usually associated with it, though. I use the term merely to suggest that planning agency involves the capacity to consider oneself as existing at different times, which enables people to contrive plans now about what they want to do then.
}

\section{Narrative Agency and Identity-Shaping Habits}

Narrative agency, as I conceive of it, refers to a person's capacity to diachronically organize their lives around contriving and executing long term plans that are part of a larger life-story. As such, the activities that comprise a life-story strive for some degree of narrative coherence. By narrative coherence I mean that persons, by and large, have the tendency to seek some degree of unity that glues together their plans and projects in view of their life-trajectory taking the form of an unfolding story. Needless to say, the demands for narrative coherence cannot be set too high; otherwise most of us would be in danger of failing to live up to the task. ${ }^{10}$ Identity-shaping habits, or so I hope to show, are efficacious means to attain at least a minimal degree of narrative coherence without having to deliberatively juggle all the moving parts of a life-story. A person's narrative agency is, then, constituted by their interrelated modes of thought and action that stretch back and forth in time, composing elements of an unfolding story.

To motivate the link between narrative agency and identity-shaping habits, and to see what work identity-shaping habits can and cannot do, I draw on Schechtman's (1996) widely discussed and sensible distinction between two related, yet distinct questions that are occasionally conflated when pondering a person's identity.

What Schechtman calls the reidentification question seeks metaphysically necessary and jointly sufficient conditions of numerical identity over time. The most frequently endorsed Neo-Lockean answer to the reidentification question typically looks something like this:

person $x$ at time $t$ is numerically identical to person $y$ at time $t^{*}$ if and only if $x$ at $t$ and $y$ at $t^{*}$ are related via non-branching psychological continuity. ${ }^{11}$

For the purposes of answering the reidentification question what matters is, on the one hand, the psychological continuity relation's logical form, i.e. the relation's capacity to properly connect different temporal person-stages such that a later person-stage logically counts as the continuant of a

\footnotetext{
${ }^{10} \mathrm{My}$ claim here is again ontological, not normative. So I remain agnostic concerning the question as to whether the goodness of a life is linked to the degree of narrative coherence it contains. Such normative questions are interesting and important. However, for my purposes they remain subsidiary since I am concerned only with offering an ontological analysis of the link between narrative agency and identity-shaping habits.

11 The non-branching qualifier to psychological continuity is sometimes added to circumvent fission scenarios. I do not mean to claim that psychological continuity views contain the right answer to the reidentification question. This is simply to illustrate what a widely held answer to the reidentification question looks like.
} 
former person-stage (or, for that matter, a former personstage logically counts as the ancestor of a later person-stage). Such psychological continuity relations hold in principle across metaphysically possible worlds. On the other hand, the connections typically included in psychological continuity theories are memory connections, connections between intentions and the resulting actions, and those between the different temporal moments of a persisting psychological state, as well as persisting dispositions. So the content of psychological continuity relations also matters in ensuring one's numerical identity. ${ }^{12}$ Since identity-shaping habits are also partly constituted by their content (recall Klea's intentions and dispositions related to cycling), they would presumably be part of what constitutes psychological continuity on these views. Identity-shaping habits are, however, not metaphysically robust enough to be translatable into a logical form analogous to non-branching psychological continuity. This is so, as I pick up in item (vi) of the conceptualization of identity-shaping habits to be found below, because their close relation to one's actual embodiment prevents them from holding across metaphysically possible worlds. So identity-shaping habits can only do so much in tackling the reidentification question.

Schechtman's characterization question, on the other hand, seeks qualitative features, or characteristics, that make someone the distinct person they are. These features usually include defining actions, experiences, values, and character traits that are so distinctive of someone that they contribute significantly to their identity. It makes sense, then, to call the kind of identity in question practical since the contrast to numerical identity as a metaphysical issue becomes clearer that way. The following paradigmatic answer to the characterization question casts our practical identity in terms of life stories, suggesting that this form of practical identity is akin to what I have earlier called narrative agency:

person $x$ at time $t$ is practically identical to person $y$ at time $t^{*}$ if and only if a sufficient number of narrative characteristics, such as actions, thoughts, character traits, convictions, properties, responsibilities, etc. that have been attributed to $x$ at $t$ can still be attributed to $y$ at $t^{*}$, securing a minimal degree of narrative coherence.

The reidentification question, then, emphasizes the formal, metaphysical structure of a person's identity over time that supposedly holds across possible worlds, whereas the characterization question emphasizes the contingent, practical structure of a person's narrative agency. Importantly, accounts of reidentification and characterization can come apart: Persons cannot become someone else with regards to

$\overline{12}$ I am grateful to an anonymous referee for urging me to clarify this. the reidentification question, and, at the same time remain numerically identical - they would cease to exist. But persons can become someone else with regards to the characterization question, and at the same time remain numerically identical. Say Mary underwent a transformative, religious conversion. Her character has changed so significantly that she no longer considers herself to be the person she once was. Since her core convictions then are incongruent with her core convictions now, her striving for narrative coherence does not allow for a single person enacting and narrating what have become two separate life stories. So there is a disconnect between what has essentially characterized Mary before and what characterizes her after the conversion. Nonetheless, in the reidentification sense, Mary remains numerically identical to her former self, since she is still logically connected to her former self via perpetual nonbranching psychological continuity. This holds true even though the content of the psychological continuity relation that still formally connects her temporal person-stages has changed to the point of incoherence. Perpetual non-branching psychological continuity, then, does not guarantee narrative agency. Sometimes, however, similar cases are portrayed conversely. Neo-Lockean psychological continuity theories occasionally incorporate the possibility of someone becoming a different person given a radical enough change in their psychological make-up. Think of Parfit's Nineteenth Century Russian:

In several years, a young Russian will inherit vast estates. Because he has socialist ideals, he intends, now, to give the land to the peasants. But he knows that in time his ideals may fade. To guard against this possibility, he does two things. He first signs a legal document, which will automatically give away the land, and which can be revoked only with his wife's consent. He then says to his wife: 'Promise me that, if I ever change my mind, and ask you to revoke this document, you will not consent'. He adds: 'I regard my ideals as essential to me. If I lose these ideals, I want you to think that I cease to exist. I want you to regard your husband then, not as me, the man who asks you for this promise, but only as his corrupted later self. Promise me that you would not do what he asks' (Parfit 1984, p. 327).

On most narrative views, however, such allegedly identity-undermining disruptions in psychological continuity need not erode one's narrative agency. If Parfit's Nineteenth Century Russian has a good story to tell about his change of heart, he could remain the same narrative agent. Narrative agency is, then, more robust than psychological continuity when it comes to significant personality changes-provided 
those changes take the form of a properly accounted for narrative. ${ }^{13}$

To see how habits can become identity-shaping as regards the characterization question, we need to know more about what characterizes someone in such a way that it constitutes their narrative agency. On Schechtman's refined view of narrative agency,

we constitute ourselves as persons by forming a narrative self-conception according to which we experience and organize our lives. This self-conception and its operations are largely implicit and automatic. As we are socialized into human culture, we are taught to operate with a background conception of ourselves as continuing individuals, leading the lives of persons. What this means more specifically is that we experience the present in the context of a larger life-narrative. In order to have a narrative self-conception in the relevant sense, the experienced past and anticipated future must condition the character and significance of present experiences and actions. When I have a selfconstituting narrative, what happens to me is not interpreted as an isolated incident, but as part of an ongoing story (Schechtman 2007, p. 162, my emphases).

To subsequently relate what I take to be the three most relevant features of narrative agency to identity-shaping habits, I first bring home the message concisely. Narrative agency consists in:

(a) Forming an implicit, automatic narrative self-conception that shapes our experiences.

(b) Having been socialized into viewing ourselves as persons persisting through time.

(c) Integrating past, present and future via planning agency into a larger life-story.

Narrative agency, as we have seen, paints a more complicated and multi-layered picture of psychological continuity than Neo-Lockeans typically give. Doing justice to this complexity, I hope to show that in many ways our narrative agency is cashed in terms of identity-shaping habits. It is time, then, to lay out a conceptualization of identity-shaping habits. Admittedly, the following catalogue of features I take to approximate a constitutive conceptualization of identityshaping habits remains incomplete and provisional. Nonetheless, it hopefully captures the essence of identity-shaping habits. So, in addition to Matthews' (2017) core features that

\footnotetext{
13 I am grateful to an anonymous referee for drawing my attention to this feature of narrative views.
}

characterize habits in general, let us carve out six defining features that distinguish identity-shaping habits in particular.

Identity-shaping habits

(i) contribute to one's self-characterization, either explicitly by contributing to expressing oneself as the person one is, or (inclusively) implicitly by playing a distinctive role in one's life;

(ii) influence one's unified perspective on life, anchored in one's self-perception;

(iii) are voluntary expressions of what we care about such that we are concerned to manage their expression, whether we care about preserving them, or care about removing them;

(iv) involve a significant degree of commitment that is not easily abandoned, requiring regular performance (not necessarily high frequency or high-level performance) over a relatively long period of time such that they gain narrative import;

(v) are reason-receptive, as in people can readily give reasons why they engage in the identity-shaping habit in question, and how this relates to their life-story;

(vi) change one's embodiment enduringly, at least for the time of their performance.

I now go through each defining feature in more detail, arguing how identity-shaping habits are constitutively linked to narrative agency.

(i) In forming a narrative self-conception, we need narrative content to fill our life-story with. Since stories call for guiding themes, they require us, as the narrators and actors we simultaneously are, to develop distinctive future-directed plans that play basic roles in organizing and coordinating our activities over time. Identity-shaping habits are suitable candidates to do so since they allow us to form a narrative selfconception that helps us find things we can both perform synchronically and identify with diachronically. Think of how Klea, after having cycled for some time, self-characterizes as a cyclist.

(ii) Narrative agency involves having a, in varying degrees, unified perspective on life. Identity-shaping habits alter this unified perspective insofar as the world is increasingly perceived through the lens of what one habitually identifies with. As a cyclist, Klea perceives roads as potential bike trails, for example. Identity-shaping habits thus not only play an active role in constituting our abstract sense of who we are and the stories we enact and tell about ourselves. Also, on a more basic level, identity-shaping habits color our look on the world in ways distinctively tai- 
lored towards the actions and thoughts we habitually identify with.

(iii) As voluntarily expressions of what we care about, identity-shaping habits presuppose a narrative selfconception in that " $[t]$ he outlook of a person who cares about something is inherently prospective; that is, he necessarily considers himself as having a future" (Frankfurt 1982, p. 260). As deliberatively chosen patterns of action, identity-shaping habits are relevant parts of expressing what we care about, since we devote significant amounts of time to them. As such, we at least implicitly express our endorsement and appreciation of the regularly performed action. If Klea did not deeply care about cycling, she surely would not spend so much time doing it. Some unwanted habits, however, despite being part of the distinct people we are, do not express what we care about. In fact, certain habits are notorious precisely because we care about getting rid of them. Addictive habits, for example, or habits that lead to behavior we disvalue, such as being in the habit of losing things or speaking on top of other people, come to mind. Identity-shaping habits as I conceive of them, however, are those that reverberate through our narrative agency such that we are concerned to manage their expression; i.e., we actively try preserving or removing them. In the cycling example, Klea is likely at some point to develop some habit within her cycling-some sloppiness in her cycling technique, say-which is counterproductive. Such a habit goes against what she cares about, and so she will be motivated to rid herself of it, thereby further shaping, albeit in a minor way, her narrative agency as a cyclist. ${ }^{14}$

(iv) The autonomous and voluntary acquisition of identity-shaping habits that involves significant levels of commitment fits well with the narrative structure of our lives, since these habits aspire to completion and fulfillment. Identity-shaping habits inform our goals and purposes; more generally, they contribute to creating the characteristically prospective outlook on, and retrospective review of, our lives. This entails an entanglement with the narrative structure of our lives that steers us to committing ourselves to, and preventing ourselves from, easily abandoning habits once they have become identity-shaping. Developing a significant level of commitment takes time. So hab-

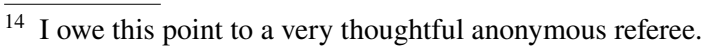

its need temporally extended performance to unfold their identity-shaping potential. ${ }^{15}$

(v) Narrative agency includes the integration of past, present and future actions via planning agency into a larger life-story. Even though this integration does not require an explicit articulation of identityshaping habits into a coherent whole, we will, upon request, be able to give at least a minimally informative account of how they fit. In reasoning such an account, we revert to character traits and core convictions, among other things. Klea, for example, might reason that she cycles regularly because she has always wanted to live a healthy life, and she is convinced that outdoor sports is conducive to her well-being.

(vi) What I have earlier, inspired by Matthews (2017), called the internal alteration feature, will now be further developed and tailored towards identityshaping habits and narrative agency. Since our physiological make-up shapes the way we navigate the world, narrative agency depends in a great many ways on our embodiment. The cognitive science of embodied cognition (Clark 1997, 1999; Lakoff and Johnson 1999; Shapiro 2014) tells us that people's mental features are deeply dependent on their bodily features. A physiological understanding of people's minds thus inevitably involves not only an understanding of the brain, but an understanding of the entire feedback loop between brain and peripheral systems. So a person's physiological make-up including, but not restricted to, their brain plays a significant, physiologically constitutive role of their cognition (Wilson and Foglia 2017). As narrative agents, embodied in dynamic systems that constantly interact with the environment, we are highly susceptible to physiological changes due to recurring thoughts and actions. Engaging in identity-shaping habits is, then, very likely to facilitate enduring changes to our embodiment, since such activities have an impact on neural plasticity, i.e. the capacity of the nervous sys-

\footnotetext{
15 I earlier said that the present account of identity-shaping habits is ontological and practical in nature. An anonymous referee pointed out that features (iii) and (iv) do contain normative elements. Caring involves a positive and stable evaluative stance towards certain things and activities; and commitment, too, implies being responsive to normative action-guiding reasons. The caring and commitment features of identity-shaping habits are, then, norm-structuring, while they remain evaluatively agnostic as to the actual content of what one cares about or commits oneself to. Ascertaining that caring and commitment is norm-structuring is to draw attention to deeply architectural features of narrative agency without thereby making evaluative claims about the goodness or badness of these features or how they are employed.
} 
tem to modify itself, functionally and structurally, in response to experience and injury (von Bernhardi et al. 2017). Since identity-shaping habits take up significant amounts of physiological and psychological resources, it becomes clear how identity-shaping habits such as Klea's cycling not only significantly change her physical constitution but also her psychological make-up; i.e., her entire embodiment. In a way, then, these enduring internal changes to a person's embodiment provide the physiological basis for the contribution of identity-shaping habits to one's self characterization, and their influence on one's unified perspective on life. The close relation between embodiment and identity-shaping habits further emphasizes their practical (rather than metaphysical) relevance. Consider that (Neo-)Lockean views of personal identity that take non-branching psychological continuity as securing personal identity are metaphysically defended using body swapping cases like the Prince and the Cobbler. Klea's identity-shaping cycling habit, however, has a crucial impact on her actual embodiment such that her narrative agency could not be transferred from one body to another in the way psychological continuity as a metaphysical notion allegedly could. Qua constraints on contingent empirical facts that identity-shaping habits elicit in one's embodiment, one's actual physical make-up cannot be successfully imagined away to isolate necessary and jointly sufficient conditions of personal identity that hold across metaphysically possible worlds.

I now briefly turn to a peculiar additional feature of identityshaping habits that does not directly fit in with any of the previously mentioned defining features. Identity-shaping habits encompass actions that we are often synchronically unaware, yet diachronically aware of. This feature, perhaps, pertains to narrative coherence in that it might help explaining the social predictability and stability narrative agents typically display.

\section{Social Predictability and Stability}

Bratman says that "one might be reflective about one's motivation at any one time and yet not be a planner who projects her agency over time" (Bratman 2000, p. 42). Identity-shaping habits peculiarly reverse this non-narrative tendency by constituting actions and thoughts that one is synchronically unaware, yet diachronically aware of. Recall our example where Klea frequently lets her mind wander while riding her bike, turning her attention to things entirely unrelated to cycling. Then again, she is very much aware of her being a cyclist and organizes her life around that awareness. ${ }^{16}$

The tendency to regularly perform actions one is synchronically unaware, yet diachronically aware of helps forming predictable actions in recurring settings, and so contributes to agential stability. Identity-shaping habits link the formation and execution of plans. Think of Klea's plan to cycle every Tuesday afternoon and the later execution thereof. Interestingly, sticking to previously formed plans is no passive, automatic psychological mechanism. Rather, it actively helps ensuring one's narrative coherence. Along those lines, in his account of agency Bratman acknowledges that planning typically concerns specific courses of action over time, involving a "commitment [to] a certain kind of action on certain kinds of potentially recurrent occasions" (ibid., 41). He further says that "the characteristic stability of such intentions and policies normally induces relevant psychological continuities of intention and the like. In these ways our plans and policies play an important role in the constitution and support of continuities and connections characteristic of the identity of the agent over time" (ibid., 47). The idea that habits are indispensable to social life in that they help developing and upholding the norms that govern social practices goes back to Aristotle. Acting habitually in accordance with the demands of the social setting at hand solidifies the relevant social norms and expectations. Predictability and stability are generally useful features in social settings since they allow us to anticipate future interactions and facilitate all sorts of interpersonal arrangements. Part of our narrative agency may depend very much on how we are conceived of, and classified, by others. Perhaps the stability resulting from identity-shaping habits supports these sorts of characterizations and stable outside classifications. That way identity-shaping habits allow social agents to anticipate people's core behavioral patterns in recurring settings. Accordingly, their behavior will largely cohere with their identity-shaping habits, preventing the need for inconvenient ad hoc adjustments, and smoothening interactions. Identityshaping habits, reminiscent of what Bratman calls personal policies, play a pivotal role in coordinating and organizing people's lives and thus contribute to their narrative coherence. Our tendency to seek narrative coherence might thus draw us to live socially predictable and stable lives.

\footnotetext{
${ }^{16}$ Synchronic unawareness is a typical feature of habits in general. One is, for example, usually unaware of, or at least inattentive to, the motion sequences of tying one's shoelaces. Diachronic awareness, though, is not a typical feature of habits in general, but appears typical of identity-shaping habits.
} 


\section{Concluding Remarks}

I have sketched a view of how identity-shaping habits crucially form one's narrative agency. In so doing, I developed a conceptualization consisting of six defining features, where identity-shaping habits (i) contribute to one's self-characterization; (ii) influence one's unified perspective on life; (iii) express what one cares about; (iv) involve a significant degree of commitment; (v) are reason-receptive; and (vi) change one's embodiment. At the heart of this conceptualization lies the idea that identity-shaping habits induce enduring internal changes to one's embodiment that provide the physiological basis for their contribution to one's self-characterization, and their influence on one's unified perspective on life.

I have presented reasons to find this view attractive, having to do with its coherence with widely held accounts of personhood and practical identity. In subsequent work I hope to explore the normative dimension of identity-shaping habits in its relation to the good life.

Acknowledgements I am grateful to the thoughtful referees at Topoi for their constructive feedback that helped improving an earlier version of this article. Special thanks to Owen King for insightful written input and fruitful discussions.

Funding No funding.

\section{Compliance with Ethical Standards}

Conflict of interest The author declares that he has no conflict of interest.

Research Involving Human and Animal Rights This article does not contain any studies with human participants or animals performed by any of the authors.

Open Access This article is licensed under a Creative Commons Attribution 4.0 International License, which permits use, sharing, adaptation, distribution and reproduction in any medium or format, as long as you give appropriate credit to the original author(s) and the source, provide a link to the Creative Commons licence, and indicate if changes were made. The images or other third party material in this article are included in the article's Creative Commons licence, unless indicated otherwise in a credit line to the material. If material is not included in the article's Creative Commons licence and your intended use is not permitted by statutory regulation or exceeds the permitted use, you will need to obtain permission directly from the copyright holder. To view a copy of this licence, visit http://creativecommons.org/licenses/by/4.0/.

\section{References}

Armitage C, Conner M (2001) Efficacy of the theory of planned behaviour: a meta-analytical review. Br J Soc Psychol 40:471-499

Bratman M (1989) Intention and personal policies. Philos Perspect $3: 443-469$
Bratman M (2000) Reflection, planning, and temporally extended agency. Philos Rev 109(1):35-61

Clark A (1997) Being there: putting brain body and world together again. MIT Press, Cambridge

Clark A (1999) Embodied, situated, and distributed cognition. In: Betchel W, Graham G (eds) A companion to cognitive science. Blackwell Publishing, Malden, pp 506-517

Di Nucci E (2013) Mindlessness. Cambridge Scholars Publishing, England

Douskos C (2017a) Habit and intention. Philosophia 45(3):1129-1148

Douskos C (2017b) Pollard on habits of action. Int J Philos Stud 25(4):504-524

Douskos C (2017c) The spontaneousness of skill and the impulsivity of habit. Synthese 1-24

Felletti F (2019) Habitual actions as a challenge to the standard theory of action. Manuscript submitted for publication

Frankfurt H (1971) Freedom of the will and the concept of a person. J Philos 68(1):5-20

Frankfurt H (1982) The importance of what we care about. Synthese 53(2):257-272

Kalis A, Ometto D (2019) An Anscombean perspective on habitual action. Topoi 1-12

Lakoff G, Johnson M (1999) Philosophy in the flesh: the embodied mind and its challenge to western thought. Basic Books, New York

Lewis D (1976) Survival and identity. In: Rorty A (ed) The identities of persons. University of California Press, Berkeley, pp 17-41

Locke J (1694/1975) Of identity and diversity. In: Nidditch p (ed) An essay concerning human understanding, Chapter XXVII. Clarendon Press, Oxford, pp 311-333

Matthews S (2017) The significance of habit. J Moral Philos 14(4):394-415

Parfit D (1984) Reasons and persons. Oxford University Press, Oxford

Pollard B (2006) Explaining actions with habits. Am Philos Q 43(1):57-69

Schechtman M (1996) The constitution of selves. Cornell University Press, Ithaca

Schechtman M (2007) Basic survival: a refinement and defense of the narrative view. In: Hutto D (ed) Narrative and understanding persons. Cambridge University Press, Cambridge, pp 155-178

Shapiro L (ed) (2014) The routledge handbook of embodied cognition. Routledge, London

Shoemaker S (1970) Persons and their pasts. Am Philos Q 7:269-285

Shoemaker S (1984) Personal identity: a materialist's account. In: Shoemaker S, Swinburne R (eds) Personal identity. Blackwell, Oxford, pp 67-133

Shoemaker S (1997) Self and substance. Philos Perspect 11:283-319

Shoemaker S (1999) Self, body, and coincidence. Proc Aristot Soc S73:287-306

Snow N (2006) Habitual virtuous actions and automaticity. Ethical Theory Moral Pract 9(5):545-561

von Bernhardi R, Bernhardi LE, Eugenín J (2017) What is neural plasticity? In: von Bernhardi R, Eugenín J, Muller K (eds), The plastic brain. Advances in experimental medicine and biology, vol 1015. Springer, Cham, pp 1-15

Wagner N-F (2019) Against cognitivism about personhood. Erkenntnis 84(3):657-686

Wagner N-F, Northoff G (2014) Habits: bridging the gap between personhood and personal identity. Front Hum Neurosci 8:1-12

Wilson R, Foglia L (2017) Embodied cognition. In: EN Zalta (ed) The stanford encyclopedia of philosophy (spring 2017 edition). Springer, New York

Publisher's Note Springer Nature remains neutral with regard to jurisdictional claims in published maps and institutional affiliations. 